\title{
JOURNAL OF ADVANCEMENT IN
}

\section{ENGINEERING AND TECHNOLOGY}

Journal homepage: http://scienceq.org/Journals/JAET.php

\section{System Thinking-System Dynamics for Sustainable Energy Planning in the Developing}

\section{Economy}

\section{Titus Kehinde Olaniyi*,}

*Corresponding author: Titus Kehinde Olaniyi

ABUAD Integrated Resources,

Afe Babalola University Ado-Ekiti (ABUAD)

Ado-Ekiti, Ekiti State, Nigeria.

Tel: +234 (0) 8069393484

E-mail: tkolaniyi@abuad.edu.ng

Received: January 10, 2014, Accepted: January 20, 2014, Published: January 20, 2014.

\section{ABSTRACT}

This article describes the importance of System Thinking (ST)/System Dynamics (SD) in addressing the complex sustainable energy planning issues with special focus to Developing Economy (DE). Many DE are undergoing dramatic changes in socio-economic policies such market liberalisation, financing and the incorporation of grounded externalities such as the environmental implications of energy projects. The article articulates the inherent limitations of traditional energy planning tools and reviews the underlying dynamics of Sustainable Energy Development (SED) in the DE. It argues that the traditional energy policy formulation that focuses on the present decision without identifying how past policies created the present complexities fail to guide future decisions. It position that the past energy development trends witnessed in the developed nations contradict the notion of SED. The major impediments to SED in the DE are inappropriate technology; complex social organisation; environmental (energy) and resource degradation, inadequate and confused investment directions amongst others. The proposed methodological approach analyses the dynamic forces that impinge on energy systems and seeks to improve the decision making process. This article fills an important gap in the literatures by pinpointing the pertinent issues that need addressing for SED in the DE.

Keywords: System Thinking / System Dynamics, Sustainable Energy Development, Energy and Developing Economies.

\section{INTRODUCTION}

This article describes the importance of System Thinking (ST)/System Dynamics (SD) in addressing the complex sustainable energy planning issues with special focus to Developing Economy (DE). Many DE are undergoing dramatic changes in socio-economic policies such market liberalisation, financing and the incorporation of grounded externalities such as the environmental implications of energy projects. Traditional energy policy formulation that focuses on the present decision without identifying how past policies created the present complexities will fail to guide future decisions.

More so, the past energy development trends witnessed in the developed nations contradict the notion of SED. The underlying principles of sustainable development and its dichotomy have been articulated in literature [1]. Problems of Sustainable Energy Development (SED) and the various inherent complexities as it pertains to DE deserve special attention.

\section{Historical and Projected Disparity of Energy Development}

Although firewood was the energy form used by pre-historic peoples, solar energy was the most influencing energy since the dawn of civilisation due to its infinite nature. Industrial and technological revolutions changed the mix and magnitude of the energy supply remarkably. The energy eras can be grouped into three: wood; coal; petroleum-gas fuels although there are no distinct discontinuities between the three main eras. Prehistoric peoples used wood as the source of energy for space heating. The fossil fuel energy scene started with coal as cheap and abundant energy resource. The industrial and technological revolutions led to intensive energy use in the production of artefacts that tremendously increased the usage of coal. Introduction of crude oil in the 1860s led to a gradual use of crude oil over coal. Then, the use of oil as boiler fuel and the development of internal combustion engines began to emerge. Oil overtook coal as the dominant fuel in the 1960's. The use of natural gas came to the energy scene in 1930s due to the technological development of long distance, low-cost gas pipelines. Commercial nuclear power for electricity generation came on the scene in the 1950's.

Nuclear was perceived as a clean energy technology capable of overcoming finite resources problems of traditional fossil fuels (i.e. coal, oil or gas). Events reveal that despite the worldwide electrification or nuclear driven hydrogen fuels programmes, nuclear contribution to the total energy consumption is still significantly low in the OECD (mainly concentrated in USA, France and UK) nations and much more so in the DE. Reasons for 
low uptake of nuclear contributions span from issues such as safety, security, political, cost, expertise (technology and intellectual) and waste disposal. Although not without environmental implications, gas and renewable energy are the most preferred energy sources in domestic, commercial and industrial applications. Gas and renewable energy contributions are lower when compared to other energy sources. Energy Information Administration [2] emphasised that fossil fuel will continue to play a significant role in the world energy production and consumption through 2035. The world marketed energy consumption is expected to increase by $49 \%$ (1.4\% per year) between 2007 and 2035. Hence, world energy consumption that is 522.25 x 106 in 2007 would rise to 622.49 x 106 TJ in 2020 and $779.69 \times 106 \mathrm{TJ}$ in 2035 respectively. Figure 1 is the snap shot of the historic world energy consumption in 2000, 2005 and 2007.

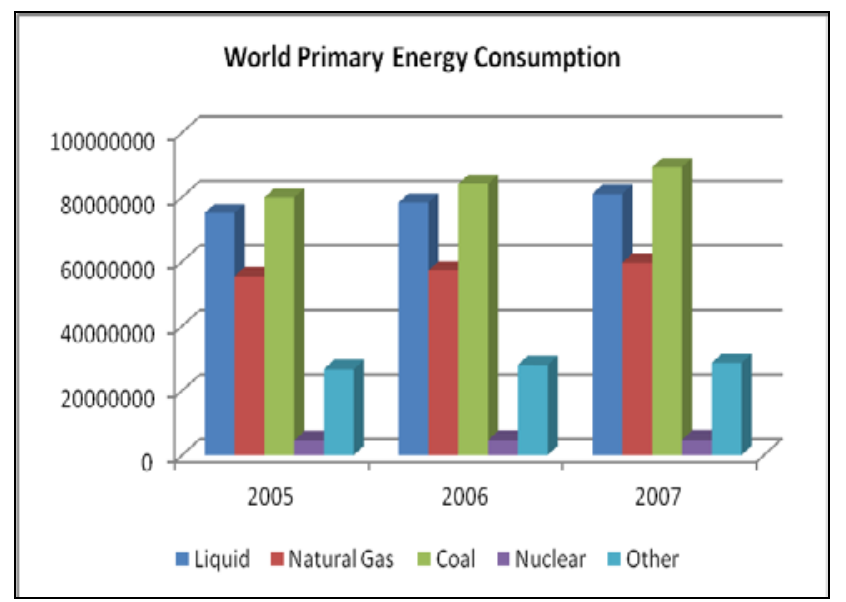

Figure 1World Primary Energy Consumption (2005, 2006 and 2007)

The figure reveals an alarming scenario in that coal has overtaken liquid (oil) fuel as the dominantly consumed fuel source. These two energy sources represent the major contributors of pollution that are responsible for climate changes. The path of economic development in DE will involve a transition from the existing low levels of energy consumption to higher levels (as urbanisation and industrialisation continues) and from traditional fuel (i.e. wood or dung) to modern (quality) commercially viable fuels. Although the global economic meltdown that began in 2008 has had profound impact on global energy demand however DE is yet to adjust their energy scenario pattern to justify the global trend. Historically, Organisation for Economic Cooperation and Development (OECD) member countries have accounted for the largest share of world energy consumption; however, for the first time in 2007 energy use among non-OECD nations exceeded that of OECD nations. The discrepancy between OECD and non-OECD energy use is expected to grow in the future; due to the more rapid growth in energy demand expected for the emerging non-OECD economies. Given the inherent economic of scale, China and India were among the two nations that were least affected $y$ the global recession as they continue to lead the world's economic growth and energy demand growth.

Most of the forecasted (2007 - 2035) growth in energy demand is expected outside OECD nations driven by strong long-term growth in Gross Domestic Product (GDP) in the emerging economies. Total non-OECD energy consumption is expected to increase by 84 per cent compared with a 14 per cent increase in energy use among OECD nations. Strong long-term growth in GDP of emerging economies in non-OECD nations will continue to encourage growing energy demand.

Liquid fuels are said remain the largest share of world energy consumption. Its share however falls from 35 per cent in 2007 to 30 per cent in 2035, as projected high world oil prices lead many energy users to switch away from liquid fuels when feasible. The use of liquids grows modestly in all end-use sectors except transportation. It is noted that $\mathrm{n}$ the absence of significant technological penetration, liquids will continue to be the source of most energy consumption. The price of light sweet crude oil (in the United States) in real 2008 dollars terms is expected to rises from $\$ 79$ per barrel in 2010 to \$108 per barrel in 2020 and \$133 per barrel in 2035. This is expected to constrain growth mostly in the oil importing DE.

World use of liquids and other petroleum is expected to grow from 86.1 million barrels per day in 2007 to 92.1 million barrels per day in 2020, 103.9 million barrels per day in 2030, and 110.6 million barrels per day in 2035. Globally, liquids consumption remains flat in the buildings sector, modest increase in the industrial sector, but slump in the electric power sector due to electricity generators reaction to rising world oil prices followed by switching to alternative fuels whenever feasible. Despite rising prices, transportation sector will witness increase in the use of liquid fuels by an average of 1.3 per cent per year, or 45 per cent overall from 2007 to 2035.

Natural gas consumption (worldwide) will increase by 44 per cent from 3058.2 x 1012 m3 or 117.8 x 106 TJ in 2007 to 4417.4 x $1012 \mathrm{~m} 3$ or 170.2 x $106 \mathrm{TJ}$ in 2035 . The industrial sector presently consumes more natural gas than any other end-use sector, and is expected to continue to do so through 2035, when 39 per cent of the world's natural gas supply is consumed for industrial purposes. Electricity generation is another important use for natural gas and its share of the world's total natural gas consumption is expected to increase from 33 per cent in 2007 to 36 per cent in 2035.

Regrettably in the absence of stringent national policies and/or binding international agreements that would curtail or reduce Green House Gas (GHG) emissions, world coal consumption of coal is expected to increase from 139.27 x $106 \mathrm{TJ}$ in 2007 to 217.34 x $106 \mathrm{TJ}$ in 2035, at an average annual rate of 1.6 per cent. Much of the projected increase in coal use is expected to occur in non-OECD Asia, which is expected to accounts for 95 per cent of the total net increase in world coal use from 2007 to 2035. Increasing demand for energy to fuel electricity generation and industrial production is expected to be largely met by coal in the region.

World net electricity generation is expected to increase by 87 per cent from 18800 TWh (terrawatthours) in 2007 to 25000 TWh in 2020 and 35200 TWh in 2035. Noting that the recession slowed the growth in electricity demand in 2008 and 2009, returning to pre-recession rates is expected by 2015 - all things being equal. Generically, OECD nations with matured electricity markets and established consumption patterns are expected to grow at a slower rate of 1.1 per cent per year compared to non-OECD nations with a forecasted average growth of 3.3 per cent per year where a large amount of potential demand remains unmet.

\section{The Principles and Diversities of Sustainable Energy Development}


The fallacy that natural capital stock (i.e. energy resources) would be held constant or improved over time is an unresolved argument in energy literatures. Environmental degradation occurs as long as the gain from the activities causing the degradation is lower than the benefits of preserving the stock in its original form. The notion that natural energy usage is yet to get to its optimum stock based on fraudulent costs-benefits analysis needs to be readdressed in order to evaluate the goal of SED as a rationale for energy conservation of existing resources. SED is view as a situation in which the development vector does not decrease over a definite time. A 'present value' is a mechanism for expressing benefits (or costs) that occur over time. It is perceived from the standpoint of the present and where the future benefits and costs are discounted - i.e. given a lower weighting relative to a similar benefit or cost in the present. Sadly, present value maximisation is consistent with the extinction of natural energy resources. Therefore, a condition for SED can be described as 'constancy of natural capital stock'.

It is important to appreciate the term "green" in understanding SED. Some forms of energy may be view as being "greener" than other forms during processing or consumption. Natural gas is considered "greener" than oil and subsequently "greener" than coal when viewed from pollutant generation perspective. However, natural gas can have considerable negative environmental implications i.e. gas flaring etc. "Green” forms of energy can also be considered from the Climate Change debate where large hydroelectric is considered as "green" despite its severe environmental impacts during construction and on-going impacts such as methyl mercury contamination [3]. The "green" concept may also be considered from the manner in which the energy is consumed. Such consideration would include incorporation of efficient use of energy that minimises energy demand, or through the utilisation of the resulting heat generation. The "green" concept supported by this article focuses on minimal environmental impacts through all stages of energy exploration, production, generation and consumption.

An extract from the World Commission on Environment and Development titled Our Common Future [4] reads:

"Humanity has the ability to make development sustainableto ensure that it meets the needs of the present without compromising the ability of future generations to meet their needs. But technology and social organisation can be managed and improved to make way for new era of economic growth. In the end, sustainable development is not a fixed state of harmony, but rather a process of change in which the exploitation of resources, the direction of investments, the orientation of technological development, and institutional change are made consistent with future as well as present needs".

Brundtland report [4] pinpoints various areas required for SED such as resource exploitation; investment direction, oriented technological development, and institutional change that are consistent with future and present needs. However, the report is inadequate in reporting the confounding dilemma affecting the SED in the DE. The main sustainable development commonality addressed from above is the dynamic nature in relation to the present and future generations. It can be argue that the salient feature from the above narration are the policy perspectives - the do's and don't of sustainable development. Various parties with diverse and sometimes opposing objectives have addressed the term 'sustainability' to communicate different policies [5]. It has been emphasised that socio-economic equity, global efficiency and development, are among the requirements for sustainable development.

Another author stated that critics of current energy and resource use go beyond the issue of climate change, resource scarcity and ecosystem disruption to how human beings live [6]. The author further argued that to some, modern industrial technology leads to climate change and underpins an unethical approach to life. It was further argued that current technology leads to social division, conflicts and alienation and underpins a consumerist society in which materialism dictates the generic norms of engagement. According to the author, others critics of energy resource use viewed the issues of climate change from radical perspectives which challenges the basic concept of development in industrial projects (economic growth for the few!). It is not an understatement to conclude that such projects as currently witnessed in the DE reinforces inequalities, marginalise the poor, exploit the weak, disadvantage minorities, and destroy the ecosystem.

\section{Limitations of Traditional Energy Planning Approaches and the Need for New Methodological Framework}

There are complicated policy decisions that arise from the need for measurement of environmental impact, and in striking a compromise between energy development, economic welfare and climate change implications. Planners and decision-makers are often unsure as to what policy route should be taking. The financing requirements, technological development and climate change concerns the application of Demand Side Management (DSM) and Integrated Resources Planning (IRP) to manage utilities. This concept is generally termed as hard (quantitative) system planning - it adopts a traditional modelling approach whose underpinning principle derived from engineering and economic disciplines. Quite a number of models proposed in literatures use optimisation [7], general simulation [8], and econometric model [9] approaches. These models were developed to understand various issues of energy planning and policy development in the DE. However, many of the models are either static, or mathematically complex and hence do not gain the acceptability of the problem owners. As a result, they are face with rejection or use purely for academic exercises without any practical applications to real life situations. Traditional energy planning models such as econometric, optimisation and general simulation models are static in their analyses and do not adequately reflect the planning needs of DE. Inherent limitations of the traditional approaches to dynamically complex energy issues in DE discussed in [1], some of which are noted below:

* Projections are based given current laws and policies

* Inability to capture the complexity in planning and decision making process

* Inadequate explanation of the causality between analysis and systems

* Lack of patterns of energy system behaviour over its lifetime

* Relevant to stable and developed economies such as the OECD

* Inability to formulate a plan or strategy for achieving a particular goal 
* Consideration of input-output, and not of gaining insight of the system

* Inability to address the dynamics of energy systems in DE dynamics are cause by the nature of inequalities in power and economic relations within and outside the economy.

The limitations outlined above call for a thorough and diligent systemic methodology, a new planning approach to support sustainable energy planning process. Sustainable energy planning tools should be capable of incorporating dynamics, feedback-loops, non-linearity, inherently long delays and the nature of socio-economic complexity of energy systems in the DE. The issues addressed above point to the need for an alternative approach to model-based decision support system frameworks. This would enhance the understanding of the complexities of sustainable energy planning in the DE. The proposed methodology and its hypothesis are stated thus:

"Dynamic Energy Systems (DES) modelling, using system thinking and system dynamics as a decision support, can provide an improved framework for sustainable energy planning and policy development in developing economies".

The proposed approach focuses on the problems of SED in the DE rather than their symptoms. It adopts Systems Thinking (ST) and System Dynamics (SD) as the underlying principles. SD is a managerial, technical, organisational and socio-economic problem solving approach originally proposed by Professor Jay Forrester of the Massachusetts Institute of Technology [10].

\section{Sustainable Energy and Implementation Dilemma in Developing Economy}

The positive causal relationship between the use of sustainable energy, economic development and population is a complex dynamics in global economy. It is asserted here that increase usage of sustainable energy is the appropriate fuel for economic development; and economic development is a prerequisite for sustaining population. Population growth that is well managed and driven by economic development would lead to increase usage of sustainable energy (Figure 2). Regrettably, the causation described here is often overlooked in DE by decision makers and their advisers.

The complex challenges of environment and development was responsible for the establishment of a global partnership that commits all nations to engage in a continuous and constructive dialogue. The dialogue inspired the need to achieve more efficient and equitable global economy with sustainable development as the policy fulcrum.

To this end, Agenda 21 [11] was adopted at the United Nations Conference on Environment and Development in Rio de Janeiro in 1992 to address environmental and developmental problems and to prepare the world for future sustainability challenges. It reflects the global consensus and political commitments at the highest governmental level. Implementation began through national strategies, planning, policies, and processes. International, regional and sub-regional organisation was also expected to support various facets of the national efforts. Agenda 21 and other environmental policies are often difficult to implement in the OECD nations as witnessed by the United States of America (USA) reluctance to adopt the Kyoto protocols.

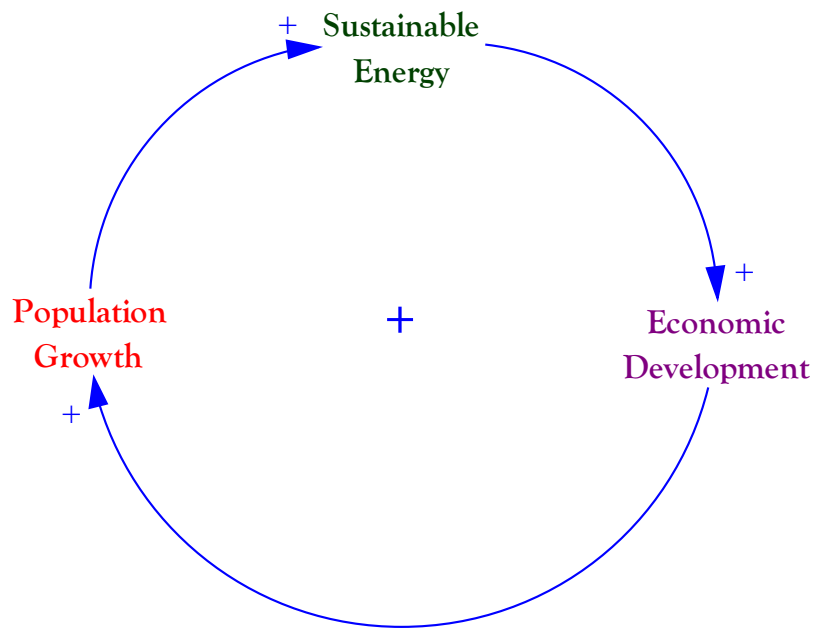

Figure 2 Positive Causation of Sustainable Energy Economic Development and Population Growth.

Further, given the diverse complexities (i.e. mounting poverty, alarming population growth, economic stagnation, escalating debt, hunger etc.) in the DE their implementations are not attracting the requisite policy attention. Given the economic, technological and institution barriers that exist in DE, the materialisation of SED policy may be significantly impeded. Section 1.4 of Agenda 21 specifically stipulates that developmental and environmental objectives would require a substantial flow of new and additional financial resources to the $\mathrm{DE}$ to cover incremental costs. There arises a significant need for financial inflow supplemented by appropriate technological and socio-political supports.

Sustainable developments are the processes by which development take place without harmful impact on the environment. The impact of energy resources, mainly oil, on world peace and political stability is difficult to exaggerate due to extreme dependence of OECD nations on oil and the consolidation of oil resources and production in the remote region of the Gulf States. The International Institute of Energy Conservation defined sustainable energy as [12]:

"The provision of energy services at the lowest life-cycle cost of the equipment where this value represents the full economic cost of the service to society as a whole".

Traditional measure of economic growth such as GDP or GNP measures real national income on a per capita basis. However, it does not include quality of life measures such as socio-technical and environmental attributes that are seriously lacking in the DE. The levelised costs of off-grid household scale renewable energy systems are cost competitive with conventional gasoline generator set and PV/wind hybrid systems - however its uptake is suboptimal in the DE.

Subsidy is an economic impediment to sustainable development. The affirmation in [13] asserted that the concept of energy subsidy has been subjected to varying interpretations and misuse due to the generic assumption of regarding subsidy as direct payment or tax concession from the government. The concept of subsidy includes government interventions that result in transfers from producers to consumers (or vice versa), which includes tariffs, price controls etc. that distorts prices and market competitiveness. The mechanism by which a subsidised project is 
financed has a bearing on its economic competitiveness. Many energy projects in DE are financed from government revenues known as 'On-budget' subsidy. It includes deficiency payments to energy product or services (output subsidy). Other subsidy may be in the form of wages, salary, energy goods etc. The value added factors of On-budget subsidy include concessionary credits, debt write-offs, subsidy to research and development, safety and environmental protections etc. 'Off-budget' subsidy includes border protection such as tariffs, quantitative import controls etc. Government-brokered sales contract is another example of 'Off-budget' subsidy. The value adding factors of 'Off-budget' subsidy include royalty concessions, income-tax concessions etc. The general implications of subsidy adoption in the DE have become the structural impediments to SED.

Another author argued that the estimate of lost revenue resulting from subsidy approximates to about 33 per cent of all oil export revenue even in oil-rich oil-exporting DE [9]. The cost of frequent occurrence of brownouts and power outages in DE are much higher than the costs of raising the prices to its free (unsubsidised) market level. Price reforms of commercial energy are paramount for SED in the DE. If the necessary steps are not taken to reduce subsidy, curtail ineffective domestic oil consumption, and preserve exports, its implications would be damaging to balance of payment, impair economic performance, and impose substantial avoided costs on DE. DE is facing great challenges; however, the challenges can be met if the principles of SED inform economic, energy resources and sustainable environmental policies. Feasible solutions from technical and commercial points of view need to be encouraged. DE needs to question the extent of science and technological progress on human welfare and economic development. Increasing welfare is primarily due to science and technology; economic growth played a secondary role.

As previously shown in Figure 2 above, improved science and technology whose output would include sustainable energy will bring about economic growth in the DE and not its reversal. Further, despite growth in economy of some DE, global and national inequities are on the increase. The conversion of natural areas to agricultural land will greatly increase due to the population growth, especially in Asia and Africa. However, in the OECD economies (mainly North America and Europe) this trend seems reversed: life expectancy is longer and the general health condition has improved. DEs are currently addressing many implications aspects of their population growth. However, the policy frameworks needed for sustainable implementation still lack the necessary supporting infrastructures including appropriate technology - a fulcrum for sustainable development.

Promotion of economic growth is the stated aim of any candidate to public office in DE, and the performance of political leaders is judged by their success to achieve the desired economic growth. The use of income per capita in measuring economic growth in the DE is often difficult because of their inherent structural 'duality' - societies, consisting of small islands of affluence surrounded by a sea of poverty [14]. The elite minorities and the poor masses live in two separate systems, and hence their energy consumption pattern differs significantly. The difference between the elite and the poor in the DE, transcend their per capita incomes to needs, aspirations, way of life etc. The elite (rich) imitate the ways of life prevailing in the developed OECD economies and have similar patterns of luxury-oriented energy wastage. In contrast, the poor masses are anxious with finding enough energy for cooking and other fundamental daily activities. Such unwanted realities have made governance and SED in DE a continuous day dreaming.

\section{Energy Market and Financial Requirements in Developing Economy}

The dynamic complexities of energy market and financial requirements in the $\mathrm{DE}$ pose a great challenge for decision makers and their advisers. To begin with, fuelwood is the dominant source of energy in rural areas of $\mathrm{DE}$, and cooking is the most energy-intensive activity. This biological source of energy is often described as non-commercial because they are not the object of commercial transaction. In many rural areas of DE, women and children usually gather twigs and branches for cooking fuel instead of buying wood. On the commercial font, the level of crude oil production mainly in the Gulf States has important consequences on the international energy market. Stability of crude oil production in the Gulf is the most powerful and deciding factor of internationally traded crude oil price and the benchmark for other forms of energy. Crude oil production has been kept relatively high in order to stabilise the energy market and lower its price. This ridiculous policy would prevent the penetration of renewable energy technologies and hence dilute the competitiveness of renewable in the international energy market. In a competitive energy market, low impact renewable energy could satisfy consumer preferences for SED. In the absence of consumer preference, it will be more difficult for renewable energy to participate in a competitive energy markets due to greater generation costs and inappropriate costing of the environmental impacts of other forms of energy.

Lower energy prices may also discourage energy efficiency measures [3]. The prices charged for energy do not reflect their true marginal cost despite substantial policy efforts to reduce or eliminate subsidies that are still abnormally prevalent in many DE. Attempts to conserve fuelwood through subsidy would generally fail if multiple uses of fuelwood were not considered. Globally, the prices of natural resources are not always linked to depletion and other economic factors are the main determinants of energy prices. It is well known that even many 'oil-rich oil-exporting' DE (i.e. Nigeria) heavily subsidise the majority of their domestic oil consumption.

Higher-energy prices can stimulate the substitution of oil, coal and natural gas with new energy technologies. This action would encourage the formation of proficient mechanisms that consider external factors within the economic system. Such policy would promote authentic and qualitative improvements in SED [16]. Environmental pressure on the world natural resources can be brought down substantially by using market-based instruments, supplemented where necessary with orders, bans, fiscal measures and agreements at national and international levels. Internationally, a policy directed to investments and trade is needed to stimulate DE to undertake indigenous technological renewal. It is however worth stating that the dependence of energy market solely on socio-economic factors implies that uniform solutions will not be optimal in all prevailing circumstances. Decision makers and their advisers in the DE would have to rethink the planning and policy framework that would sustain the energy market and promote injection of the required financial capital for SED. 


\section{Technology, Energy Conservation and Efficiency}

The early 1960s saw the beginnings of environmental concerns that resulted in the publication that warned about environmental dangers of pesticides [17]. Carson's publication triggered two parallel growths of environmental campaigners. The first is the concerns among young people, mainly from affluent backgrounds and the second is the rise in radical political ('new left') movement reflected by student protest in many parts of the world. The young objected to the mechanism of goods and service production. Their main concern was the ideological framework of conventional consumerist and materialist society. The 'new left' political movement accused the capitalists of denying society the full benefits of technology that could be effectively utilised to meet global human needs. They insisted that this is single-minded concern for the economic interests of capitalists-shareowners that owned and controlled technology. It is quite obvious that there is a conflict and interrelationship between technical (technology) means and political ends. The 'new left' also demanded for new sets of alternatives technologies to meet their currents needs and aspirations. The two arguments presented above are still constraining the DE from meeting their SED obligations on various facets.

Technology assessment for discounted energy systems and palatable organisation structures are the two significant obstacles for SED in the DE. Reliable, timely, and cost-effective supply; reduction in system vulnerability; minimum environmental impacts; and equity oriented energy supply are consistent strategies to SED that needs pursuance by energy planners in the DE. Interpreting the term 'technology transfer' as a distinct entity creates many difficulties. The process of importing advanced and appropriate technology and creating an institution mechanism, which has the capacity to absorb, adapt, sustain and ultimately improve the institution should not be seen as a passive process by both the donor and the decision makers including their advisers in the DE. Hence, the term 'technology transfer' should be replaced with 'technology sustenance' that does not imply passivity on the side of DE. Energy conservation, efficiency, and technologies are concordant with sustainability than many energy production options [1]. Conventional energy technologies involve corporate or government scale ownership with application based on economies of scale, where bigger is preferable. In contrast, renewable energy technologies are suitable to local ownership using indigenous resources on a modular basis where increment can be added as the need arises. Conditions by which the latter can be increased need to be analysed in details if decision makers are to encourage their uptake.

In many gas rich DE, inappropriate technology and a lack of coherent pricing strategies results in flaring of about 50 per cent of natural gas production [1]. Technological potential is still gigantic, but investment in the social system such as in their population will be necessary if the potentials are to be attained. Technology sustenance should be simplified into those of artefact, design, and capacity transfer which include knowledge transferred from OECD nations to DE. Intellectual transfer and retention of human knowledge and the purchase of 'know-how' rather the transfer of hardware will generally provide the greatest returns for DE. The most successful transfers would include the organisational and management systems associated with the technology to fit into the existing pattern of administration and routines in the DE. Regrettably, the organisational systems of modern corporations, international financial institutions, and national governments and industry may reflect different and incompatible priorities and values to the cultural, political, technical and religious institutions in the DE.

Adaptation of the organisational and management systems to maximise the chance that the selected technology will achieve widespread benefits without generating social conflict or disrupting the functioning of the resource may be difficult to attain. The main difficulty in technology sustenance is that many of the 'skills' involved are the result of 'acquired, experience, non-codified knowledge' - involving the 'know how' to 'know why' for technology development, operation and maintenance. Sadly, these aspects are still poorly described, captured, maintained, managed and sustained in many DE.

Energy efficiency refers to measures to conserve energy or that result in the more efficient use of energy. Some energy efficiency measures manage the time of day and level of customer demand to minimise peak requirements and overall system generation requirements. The low energy demand growth in the $\mathrm{DE}$ and the failure of utility-sponsored demand-side management has reduced the rate of growth of sales of energy efficiency products and services. However, International Institute for Energy Conservation (IIEC) reported that there are various converging factors that create a huge potential market for energy efficiency in developing and transition economies [19]. These factors include high-energy intensities, rising energy demand, capital and capacity shortages and environmental constraints including climate change. Consequently, producers, distributors, and energy service providers that have traditionally focused on OECD nations for major sales and profits must now turn to the DE and transitional economies to sustain their relevance and growth. Many DE are less energy efficient as compared to OECD nations. This was partly due to rapid industrial growth in the $\mathrm{DE}$ in the last three decades that resulted in high energy-consumption in relation to their economic output (energy-intensity). Increasing energy demand in the DE will enable promotion of energy efficiency projects designed to retrieve lost energy as the most cost-effective options for SED in the DE.

\section{Energy Supply and Demand in Developing Economy}

The usage of energy poses a dilemma in attaining SED worldwide. Energy usage is a necessity for economic growth, however the use of fossil fuel, which accounts for a significant proportion of energy consumption is a major contributor to both localised and global pollution that is resulting in climate change. In addressing the complex feedback dynamics [1] the authors addresses the inherent complexities between energy usage and climate change and further argued for a properly thought out planning paradigm and policies on energy usage and energy resource management in the DE. DE have dramatically expanded their power sector in the last four decades, however, more than two billion people living in rural area still lack the option of grid-based electricity services and those that reside in urban areas are confronted with epileptic power systems and continued reliance on inefficient and alternative power generation for survival. Given the high cost of extension of grid-based energy-utility services in the DE, [20] argued that progress in extending these services to areas not currently served remained slower than population growth. Unfortunately, attempts to 
deregulate the energy market have not attracted reliable and competent energy producers with the requisite track record.

It has been demonstrated [21] in a study conducted for Nigeria and Tanzania that there exists a simultaneous causal relationship between energy consumption and economic growth. Unless the energy supply constraints are eased, economic growth and development would remain elusive. Given the similar economic profiling as displayed by many DE, energy plays an essential role in the process of overall economic planning. In many DE, the tariff structures hardly reflect time of day or seasonal patterns of demand [14] resulting in undercharging the peak users and further imposing the need for increasing capacity requirements for the generating systems. Increase and efficient energy production could be encouraged in many DE by the introducing better producer incentives through higher energy prices. Figure 3 further expand the earlier argument in relation to the positive or reinforcing causal relationship between sustainability, economic development, population growth and the role of energy. DE needs efficient and reliable energy supply to enable and improve its sustenance. Sustainable development is a pre-requisite for economic growth and the well sought after improve healthcare would be made possible through economic development. Sustaining the increased population in the DE would require an improved healthcare. Rising population in the developing economy would attract an increased energy demand and increased demand would facilitate improved energy supply. Increased energy supplies are urgently required in the DE if sustainability is to be achieved [1].

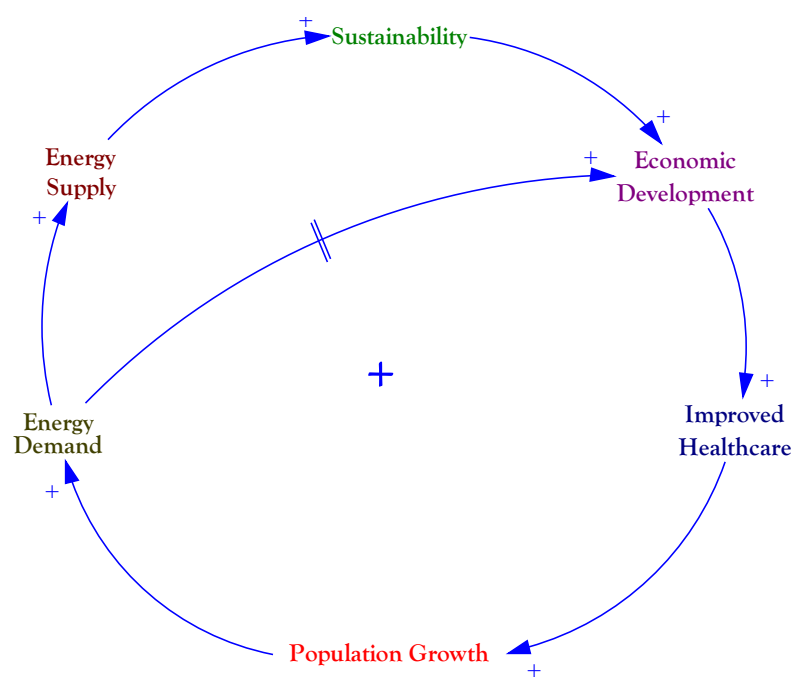

Figure 3 Positive Causation of Sustainability- Economic Development -Improved Healthcare and Energy

It is also important to emphasis the important relationship and the associated delays between energy demand and economic growth shown in Figure 3 above. Modern and forward looking DE even those that are not endowed with indigenous fossil fuel supply are creating wealth (economic development) by enabling energy demand through the use of appropriate technology, reliable market environment, political willingness etc. Undoubtedly, such linkage comes with its own inertia that causes delay in achieving the intended objectives.

There is considerable uncertainty over fossil fuel resources in the medium-term. The lifetime and global distribution vary enormously [22]:
* Oil: OPEC (Middle East)-dominated, 20-40 years; 40 years * Natural gas: CIS (Russian)-dominated, 40-70 years; 60 years * Coal: Widely distributed, 80-240 years; 200 years.

These figures are rough estimates assuming current rates of consumption, but they indicate that the sources of fossil fuel supplies with the exception of coal are insecure. If depletion of oil and gas is as stated above, the price of these fuels would rise significantly with time if alternative were not accessible. This would make a better financial case for renewable energy resources and nuclear power might look much brighter. It has often been argued since the "oil crises" of the 1970s that a nuclear power and/or renewable energy strategy should be adopted as an "insurance policy" against the insecurity of the oil and gas market. Change in energy policy direction by Tony Blair (former British Prime Minster) is an exemplar for the case for nuclear technology. In reality, the two resources are not substitutable, particularly in the transport sector. Further, the adoption of wide-scale nuclear energy in DE poses technological, security, safety, political pressures among others and many DE might fall short of the required pass mark for the adoption of nuclear technology in economic development.

The use of cogeneration as a viable source of energy for economic development [23] has been described in literature. Cogenerated heat can satisfy air and water heating demands in the residential, commercial as well as institutional sectors using on-site cogeneration, or central cogeneration with district heating, and industrial heating needs. Cogenerated heat can also provide space cooling via heat-driven absorption chillers. Cogeneration systems are similar to thermal electricity-generation systems. In most thermal electricity-generation systems, an energy resource (normally a fossil or nuclear fuel but sometimes a renewable energy resource) is converted to heat, of which a portion (normally 20 to 45 per cent) is converted to electricity, and the remainder rejected to the environment as waste heat. In cogeneration systems, depending upon the needs of the customers, part of the generated heat is use for electricity production; part is delivered as product hence resulting in the reduction of wasted heat. Cogeneration energy efficiencies (based on both electricity and heat) of over 80 per cent are achievable and it is hopeful that many DE would explore this option in their pursuit for SED.

District energy systems (which can include both district heating and district cooling systems) use central heating and/or cooling facilities to provide heating and/or cooling services for communities [24]. In a district-cooling system, a chilled fluid, normally treated water, is supplied from a central chiller plant and transported by pipeline to users of the cooling capacity, then returned for re-cooling. The chilling plant can utilise electrical chillers or heat-driven absorption chillers. In district heating systems, a similar heating loop with a central heat supply is utilised. The advantages of district energy systems over conventional heating and cooling systems include improved efficiency, reliability and safety, reduced environmental impact, and for many situations better economics. Hence, integrated systems for cogeneration and district energy are possible even in the DE.

In order to withstand a range of severe disturbances at the time of annual peak demand, heavy expenditures are often committed for operations as well as equipment and controls of the entire power system. Most of this expenditure could be avoided, 
without reducing power system security, by curtailing the demand at peak periods. Even though alternating current (ac) energy cannot be stored, fast responding inverters allow access to other forms of energy storage. Battery Energy Storage Systems (BESS) are mature technology that could fulfil this function and inverters provide the ideal interface between the direct current (dc) energy storage and the ac system [25]. Many DE are often characterised by scarce and finite energy resources and limited financial capital needed for sustainable economic growth. Industrial cogeneration could offer an opportunity for supplementing national energy resources. It is not always economical to choose cogeneration over a mix of conventional plants due to factors such as efficiency, mode of operation, availability of topping plant and manner of financing. These factors influence cash flows, which ultimately determine the economic viability of cogeneration. Hence, a detailed analysis involving the identification and quantification of incremental costs needs to be undertaken. If cogeneration is to contribute to SED in the DE, the necessary policy framework must be enacted and energy planners must adopt positive attitudes towards its implementation.

The threat of the OECD nations might not be of energy supply availability but of their impact on the environment. This argument might be true in the OECD nations; however, it is different scenario in the DE. DE constitute 77 per cent of the world population [1] but only produced 45 per cent of commercial energy and consume less than 30 per cent of the world average commercial energy and mainly utilising older technology. DE accounts for the vast majority of traditional or non-commercial fuel consumption. The world biomass consumption has historically been about 8-10 per cent of total primary commercial energy consumption. However, for DE in Africa and Asia, this percentage can be as high as 30 to 50 per cent - representing a significant amount in their energy consumption. DE is expected to account for most of the future growth in primary energy demand and hence the need for proactive planning and policy framework for addressing SED by energy planners.

Conclusion of Energy Planning and Technological Issues in Developing Economy

Review of literatures in this article reveals many facets of energy and technological policy dilemmas that are needed in addressing SED in the DE. Many DE are battling economic stagnation, rapid population growth, poverty, political instability, unemployment, and mismanagement. Energy is an essential input to agricultural production, transportation, industry, commerce and the home. The energy industry serves as a vehicle for job creation and as a stimulant for other industries. The growing increase in mobility, urbanisation of the rural area and economic integration will compound the continue dependence on energy. Therefore, reliance on energy will continue to grow in the DE. Greater use of modern and efficient forms of energy services are vital ingredients to economic development and poverty reduction in DE.

Historical evidence hypothesise that increase usage of energy and its future dependence entails burdens on the environment, health, safety, lifestyle and the type of community in which human lives. Disparities in energy use exist within and among countries; rural and urban populations; high and low income groups. There is an urgent need for policy lever to bridge these gaps. Socio-economic, technological, energy supply, demand and climate change implications are issues constraining economic growth and SED in the DE. Technological sustenance and advancements will play a significant role in shaping the market opportunities and SED in DE. Technology speed of penetration in DE will depends on the costs, appropriateness, sustenance, state of art technologies for producing and using different energy forms, political willingness amongst others. Energy systems develop very slowly because they require large amount of capital and infrastructure that can only be replaced gradually over a long period. Further issues to be resolved by energy planners in the DE include:

* Assuring and planning a medium to long-term supply of convenient and efficient energy at a reasonable economic price.

* Protecting the economy against energy supply, economic and political disruptions etc.

* Mitigation of environment impacts - emissions, land contamination and climate change.

\section{REFERENCES}

1. Olaniyi, T. K., Day, A. R., Karayiannis, T. G., Kennedy, M. S., and Fagbenle, R. O. (2008). Decision support system for sustainable energy planning in a developing economy. Ph.D thesis, London: London South Bank University. United Kingdom.

2. Energy Information Administration (July, 2010). International Energy Outlook. US Energy Information Administration. Office of Integrated Analyses and Forecasting. US Department of Energy, Washington, DC.

3. Muir, M. A. K. (2000). Sustainable Energy Development and Use: Competitive Energy Markets and the Role of Renewable Energy and Energy Efficiency. Sustainable Development in Canada. Canadian Bar Association.

4. Brundtland, G. H. (1987). Our Common Future. In the Report of the World Commission on Environment and Development, Geneva, Switzerland.

5. Langeweg, F. (1998). The Implementation of Agenda 21 'Our Common Failure'? The Science of the Total Environment. Vol. 218, pp. 227-238.

6. Elliot, D. (1997). Energy, Society and Environment. Routledge Introduction to Environmental Series. Routledge, London and New York.

7. Suganthi, L. and Samuel, A. A. (2000). Exergy based Supply Side Energy Management for Sustainable Energy Development. Renewable Energy 19, pp. 285-290.

8. Manzini, F. and Martinez, M. (1999). Choosing an Energy Future: The Environmental Impact of End-use Technologies. Energy Policy. 27, pp. 401-414.

9. Stern, D. I. (1995). The Contribution of the Mining Sector to Sustainability in Developing Economies. Ecological Economics. 13, pp. 53-63.

10. Forrester, J. W. (1961). Industrial Dynamics. MIT Press, Cambridge, Mass

11. International Institute for Sustainable Development. (1997). Assessing Sustainable Development: Principles in Practice. International Institute for Sustainable Development, Manitoba, Canada.

12. Price, B. (1999). Definition of Sustainable Energy. http://www.iiec.org/resc/senergy/index.html (March 15 1999). 
13. Steenblik, R. P. (1995). A Note on the Concept of Subsidy. Energy Policy. Vol. 23. No 6, pp 483-484. Elsevier Science Ltd.

14. Kosmo, M. (1989). Commercial Energy Subsidies in Developing Countries- Opportunity for Reform. Energy Policy. pp. 244-253.

15. Goldemberg, J. (1996). Energy, Environment and Development. Earthscan.

16. Goodland, R. (1997). Biophysical and Objective Environmental Sustainability. In: Dragun, A.K., Jacobson, K.M. (Eds.), Sustainability and Global Environmental Policy. Edward Elgar, Cheltenham, pp. 63-95.

17. Carson, R. (1965). Silent Spring. Penguin Books, London.

18. Olaniyi, T.K., Day, A., Karayiannis, T.G., Kennedy, M., and Fagbenle, R. O. (2008). Decision Support Systems for Sustainable Energy Planning in a Developing Economy: A PhD thesis submitted to London South Bank University. United Kingdom.

19. International Institute for Energy Conservation (IIEC, 1996). Opportunity Knocks: The Export Market for the Energy
Efficiency and Renewable Energy Industry. Washington. D.C., USA.

20. Lenssen, N (1993). Providing Energy in the Developing Countries. World-watch Institute, State of the World, pp. 101-119.

21. Ebohon, O. (1996). Energy, Economic Growth and Causality in Developing Countries. Energy Policy Vol. 24. No 5 pp 447-453.

22. World Energy Council (2004). 2004 Survey of Energy Resources. World Energy Council. London UK.

23. Joseph, E. and Roy-Aikins, A. (1995). Cogeneration in rural development. Energy. Vol. 20. No. 2, pp.95-104.

24. Nelson R. M. and Kainlauri E. O. (1989). District Heating with Cogeneration. ASHRAE Journal, 31, pp. 20-22.

25. Sutanto, D. and Lachs, W. R. (1998). Battery Energy Storage Systems for Sustainable Energy Development in Asia. Electric Power Systems Research. 44, pp. 61-67. 